Original article

\title{
Effects of seed traits variation on seedling performance of the invasive weed, Ambrosia artemisiifolia L.
}

\author{
William Ortmans*, Grégory Mahy, Arnaud Monty \\ Biodiversity and Landscape Unit, Gembloux Agro-Bio Tech, University of Liege, Passage des Déportés 2, 5030 Gembloux, Belgium
}

\section{A R T I C L E I N F O}

\section{Article history:}

Received 19 November 2015

Received in revised form

14 January 2016

Accepted 15 January 2016

Available online xxx

\section{Keywords:}

Achene variability

Competitive ability

Cotyledon area

Phenotypic plasticity

Seed colour

Seed mass

\begin{abstract}
A B S T R A C T
Seedling performance can determine the survival of a juvenile plant and impact adult plant performance. Understanding the factors that may impact seedling performance is thus critical, especially for annuals, opportunists or invasive plant species. Seedling performance can vary among mothers or populations in response to environmental conditions or under the influence of seed traits. However, very few studies have investigated seed traits variations and their consequences on seedling performance. Specifically, the following questions have been addressed by this work: 1) How the seed traits of the invasive Ambrosia artemisiifolia L. vary among mothers and populations, as well as along the latitude; 2) How do seed traits influence seedling performance; 3 ) Is the influence on seedlings temperature dependent. With seeds from nine Western Europe ruderal populations, seed traits that can influence seedling development were measured. The seeds were sown into growth chambers with warmer or colder temperature treatments. During seedling growth, performance-related traits were measured. A high variability in seed traits was highlighted. Variation was determined by the mother identity and population, but not latitude. Together, the temperature, population and the identity of the mother had an effect on seedling performance. Seed traits had a relative impact on seedling performance, but this did not appear to be temperature dependent. Seedling performance exhibited a strong plastic response to the temperature, was shaped by the identity of the mother and the population, and was influenced by a number of seed traits.
\end{abstract}

() 2016 Elsevier Masson SAS. All rights reserved.

\section{Introduction}

The juvenile stage represents the most vulnerable period in a plant's life cycle (Simons and Johnston, 2000; Vange et al., 2004). During this time, seedling performance is crucial and can have an impact on later life stages, and therefore affect the overall fitness of the parents (Gross, 1984; Renata D Wulff, 1986). The successful development of a seedling increases the chances for effective establishment of opportunist species or plant invaders in new areas (Fenesi et al., 2014; Skálová et al., 2012). It is therefore very important to understand what the factors are that can influence seedling performance. Variation in such performance may result from genetic variation (Biere, 1991), have a plastic origin in response to environmental conditions (Hotchkiss et al., 2008), or be caused by seed trait variation (Dolan, 1984; Harper et al., 1970; Monty et al., 2013; Roach and Wulff, 1987; Stanton, 1984).

\footnotetext{
* Corresponding author.

E-mail addresses: w.ortmans@ulg.ac.be (W. Ortmans), g.mahy@ulg.ac.be (G. Mahy), arnaud.monty@ulg.ac.be (A. Monty).
}

Seed traits, e.g., seed mass, seed size, seed colour, are known to vary considerably within various species, even among populations or individuals (Harper et al., 1970; López et al., 2008; Roach and Wulff, 1987; Simons and Johnston, 2000; Stanton, 1984; Susko and Lovett-Doust, 2000). This phenotypic variation often comes about from environmental constraints. For example, evidence has been found of clinal variations in seed traits as a consequence of local climatic conditions (Moles et al., 2007; Monty and Mahy, 2009). When the resources become limiting, a variation may appear because of trade-offs in resource allocation between seed size and seed number (Smith and Fretwell, 1974; Venable, 1992). This differential resource allocation is known as the "bet-hedging" strategy.

A large intraspecific variation in seed traits can also be an adaptive response of the plant to environmental conditions, e.g. to habitat characteristics (Tautenhahn et al., 2008), to the competition intensity (Kleunen et al., 2001), or to predation (Moegenburg, 1996). Selection can also directly promote seed variation in order to enhance the ability of a plant to survive in a wider range of environmental conditions (Fenner and Thompson, 2005). The 
production of a 'range' of seed traits is an effective evolutionary strategy that can minimize risk and increase the probabilities of reproducing in an unpredictable environment (Venable and Brown, 1988). This is particularly true for annual ruderal plant species that colonize disturbed habitats (Harper, 1977).

The consequences of seed trait variation on seedling performance may depend on environmental conditions experienced by the progeny, with performance differences between large and small seeds being greatest under adverse conditions and lower in more favourable environments (Dolan, 1984; Gross and Smith, 1991; Gross, 1984; Monty et al., 2013; R D Wulff, 1986a, 1986b). These differences would be explained by a stronger advantage of seed resources in aiding seedling development in adverse conditions versus favourable conditions where the seedlings are less stressed.

Seed traits may have different influence on seedling development. For example, seed mass may be considered a proxy of the reserves that the mother had provided to the embryo, and it is often used to account for seed variation (Simons and Johnston, 2000; Vange et al., 2004). Seed mass variation can be directly connected to germination kinetics (Harper et al., 1970; Schutte et al., 2008), but may also have an impact on seedling performance (Baskin and Baskin, 2001; Dolan, 1984; Harper et al., 1970; Monty et al., 2013; Roach and Wulff, 1987; Stanton, 1984). Another example is seed colour that has been documented to be linked to seed dormancy, with darker or more coloured seeds having a thicker seed coat and a greater dormancy than lighter seeds (Durán and Retamal, 1989; Khan et al., 1997; Powell, 1989; Wyatt, 1977). The seed coat exerts its germination-restrictive action most of the time by being impermeable to water and/or oxygen, by its mechanical resistance to radicle protrusion, or by the presence of phenolic compounds with antioxidant properties that play a protective role against degradation processes (Debeaujon et al., 2000).

The study of seed traits variation is especially important in the case of plant invasion. The seed is often the dispersal vector of invasive plant (Cain et al., 2000), and is then to the invasion process. Seed trait variation could be a major feature explaining invasive plant success, as it not only can enhance colonization at both local and regional scales, but also facilitate the exploitation of spatial and temporal heterogeneous environments (Mandák and Pyšek, 2001; Monty et al., 2013; Willis and Hulme, 2004). A better understanding of how plant invaders colonize and establish in new areas is therefore critical to prevent further invasion. However, to date, just a few studies have examined the influence of seed variation and its consequences for plant invaders (Sõber and Ramula, 2013; Susko and Lovett-Doust, 2000).

Ambrosia artemisiifolia L. (common ragweed, Asteraceae) is an annual plant that was introduced from North America to Europe more than a century ago (Heckel, 1906). The achenes of A. artemisiifolia have a central terminal beak surrounded by a ring of tiny spines (Fig. 1), probably having a dispersal role through soils and human transport (Bassett and Crompton, 1975). The species substantially spread in numerous European countries (Chauvel et al., 2006; Kazinczi et al., 2008; Smith et al., 2013; Solomon et al., 2007). It is both a weed colonizing spring crops and a ruderal plant invading open disturbed habitats, such as wastelands, roadsides or riverbanks (Bassett and Crompton, 1975). For convenience, the entire dispersal unit of $A$. artemisiifolia will be referred to as a seed.

A. artemisiifolia invasion in Europe is an especially interesting case study, as invasion success is known to be linked to seed characteristics (Fenesi et al., 2014; Fumanal et al., 2008; Guillemin and Chauvel, 2011). On top of being highly variable (Fumanal et al., 2007a; Gebben, 1965), the seeds are able to survive for many years in the soil (Bassett and Crompton, 1975), allowing the creation of a long-lasting soil seed bank. This soil seed bank ensures the

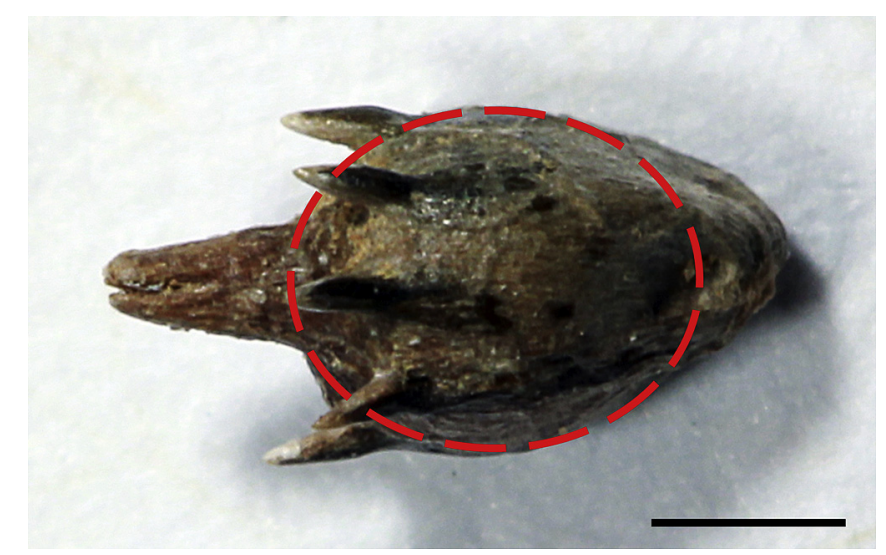

Fig. 1. Standard image of a seed of Ambrosia artemisiifolia taken to measure seed functional area and seed coat lightness. The red-dashed ellipse represents an example of the largest ellipse that could be drawn inside the seed for functional area measurement. Scale bar $=1 \mathrm{~mm}$. (For interpretation of the references to colour in this figure legend, the reader is referred to the web version of this article.)

establishment of the species for years beyond once a single successful seed production has occurred in the area (Fumanal et al., 2008). Furthermore, the species produces allergenic pollen known to be causing a health crisis in Europe, making the understanding of the mechanisms involved in invasion success highly valuable for management (Kazinczi et al., 2008; Laaidi et al., 2003; Smith et al., 2013).

Both studying how seed variation is structured as well as gaining insight into its consequences on seedling performance are essential to better comprehend the critical factors influencing seedling development in the early stage of its life, and the subsequent successful establishment of the species. Specifically, the work presented here addressed the following questions: 1) How is the seed variation structured among mothers and populations and are there geographic patterns? 2) How do seed traits influence seedling performance? 3 ) Is the influence of seed traits on seedling performance dependent on environmental conditions (i.e. the temperature)?

\section{Materials and methods}

\subsection{Seed collection}

Seeds of $A$. artemisiifolia were collected from nine populations in the Netherlands, Belgium and France (Table 1). Populations were sampled in ruderal habitats (along roadsides, riverbanks or wastelands) during the autumn of 2013. In each population, all seeds of ten randomly chosen mature individuals (i.e. mother plant) having at least 30 seeds were collected and stored in separate paper bags. Pending the start of the experiment, the seeds were stored for 6 months at $4{ }^{\circ} \mathrm{C}$.

Table 1

Provenances of the sampled populations of Ambrosia artemisiifolia.

\begin{tabular}{cllll}
\hline Latitude $\left({ }^{\circ} \mathrm{N}\right)$ & Longitude $\left({ }^{\circ} \mathrm{E}\right)$ & City & Country & Code \\
\hline 51.23493 & 4.43645 & Merksem & Belgium & $\mathrm{A}$ \\
51.12004 & 5.84034 & Echt & Netherlands & $\mathrm{B}$ \\
50.92290 & 3.21370 & Izegem & Belgium & $\mathrm{C}$ \\
47.00574 & 4.84703 & Beaune & France & $\mathrm{D}$ \\
46.29726 & 4.83344 & Mâcon & France & $\mathrm{E}$ \\
45.96413 & 5.25703 & Châtillon-la-Palud & France & $\mathrm{F}$ \\
44.74784 & 4.91819 & Ramière & France & $\mathrm{G}$ \\
44.43927 & 4.67990 & Donzère & France & $\mathrm{H}$ \\
44.09044 & 4.73589 & Montfaucon & France & $\mathrm{I}$ \\
\hline
\end{tabular}


For each harvested mother plant, the total number of seeds was counted using a Contador (Pfeuffer ${ }^{\circledR}$, Kitzingen, Germany). Ten seeds from a mother plant were randomly selected. Seeds without an embryo were excluded by testing their resistance to light hand pressure on the seed surface (Fumanal et al., 2007b; Guillemin and Chauvel, 2011). Each excluded seed was replaced by another randomly chosen seed. In total, 900 seeds were selected.

\subsection{Seed measurements}

In order to best characterize seed variation structure, three seed traits were chosen that are known to have different origins and varying physiological implications in the development of the future seedling. First, the mass of each seed was measured to the nearest $10^{-4} \mathrm{~g}$ (XA105 DualRange, Mettler Toledo ${ }^{\circledR}$, Viroflay, France). In addition to the seed mass, we assessed the seed functional area. This measurement corresponds to the area of the biggest ellipse inscribed in the seed picture. The aim is to have a measurement of the space available for the embryo without outgrowths that commonly encompassed in seed mass measurements. Seed functional area was determined with ImageJ (National institute of Health, Bethesda, Maryland, USA) from pictures of each seed taken using an SLR camera (Lens EF $50 \mathrm{~mm} \mathrm{f} / 1.8$, Canon ${ }^{\circledR}$, Tokyo, Japan) mounted on a tripod with a white background (Fig. 1). Each picture had a resolution of $1936 \times 1288$ pixels ( 2.49 megapixels). Finally, the seed coat lightness was measured in the same ellipse drawn for the seed functional area. It was recorded in shades of grey, on a scale from 0 (darkest black) to 255 (purest white). It is calculated as the mean sum of red, blue, and green values of each pixel included in the ellipse.

\subsection{Growth chamber experiment}

Each seed was sown in an individual pot on a substrate saturated with water. The substrate was housed in 20\% universal potting soil (Terofor, La plaine Chassart, Wagnelée, Belgium) and $80 \%$ river sand (Dololux, Echt, Netherlands) with a total of $25 \mathrm{ml}$ of substrate. The pots with the seeds were stratified over the course of 3 weeks at $4{ }^{\circ} \mathrm{C}$ and in darkness.

After stratification, the pots were placed in two contrasted temperature treatments in controlled growth chambers (Fitotron ${ }^{\circledR}$ SGC 120, Weiss Technik UK, Loughborough, United Kingdom). Five seeds of each mother plant were placed in a chamber. The experiment lasted from February 24th 2014 to April 22nd 2014. One chamber had colder conditions, $15^{\circ} \mathrm{C}$ day $/ 10^{\circ} \mathrm{C}$ night cycle, and the other had warmer conditions, $25{ }^{\circ} \mathrm{C}$ day $/ 20^{\circ} \mathrm{C}$ night cycle. Both chambers were set up to have a photoperiod of $16 \mathrm{~h}$ day $/ 8 \mathrm{~h}$ night with a luminosity of $450 \mu \mathrm{E}$ during the day. A relative humidity of $70 \%$ was imposed to avoid a rapid desiccation of the watered pots. After four weeks of life, each seedling received $3.15 \cdot 10^{-5} \mathrm{~L}$ of a balanced NPK fertilizer (6-5-5, Substral ${ }^{\circledR}$, Ecully, France) through irrigation water to avoid nutrient stress.

During the experiment, traits that translate different components of overall performance were measured. Firstly, time to germination was assessed. The ability of seeds to quickly germinate when the appropriate environmental conditions were met may facilitate the establishment of invasive plants (Rice and Dyer, 2001). This was considered especially relevant for A. artemisiifolia as it has an opportunist behaviour (Bazzaz, 1974). The germinations were recorded daily and a seed was considered germinated when a radicle was visible. The time to germination was measured as the number of days from the start of the experiment in a growth chamber to germination of each seed.

Secondly, foliage cover was measured exactly fourteen days after seed germination. This was thought to be a proxy of early competitive ability that would correspond to a plant's capacity to quickly impose competition to other plants. As it is independent of germination kinetics, these values would be related to the intrinsic development speed of the seedling. The measurements came from standard pictures of the seedlings. Photographic material and picture quality were the same as that used for seed characteristics. The pictures were taken from the top of the seedling in order to view the entirety of the foliage on a black background. Then, the foliage cover $(\mathrm{cm} 2)$ was measured using the thresholder function of Image J that separated the green colour from the background (Fig. 2).

Finally, the above ground dry biomass was measured as a proxy for overall seedling performance. It is a solid predictor of pollen and seed production (as demonstrated by Fumanal et al., 2007a). The plants were cut and dried for $48 \mathrm{~h}$ at $65{ }^{\circ} \mathrm{C}$ at the end of the experiment, then weighed to the nearest $10^{-4} \mathrm{~g}$.

\subsection{Data analyses}

The seed traits and seedling response variations were analyzed with descriptive statistics (mean, standard error of the mean, minimum, and maximum). The Pearson correlation between each seed trait was calculated. To analyze the influence of the population, the identity of the mother plant, and the intra-mother variability on seed traits, a two-ways nested analysis of variance (ANOVA) was performed for each trait using population as a random factor and the mother plant as a random factor nested in population. To test if there was a geographical pattern of variation of the seed traits, the Pearson correlation between each seed trait was calculated with latitude. It was also tested whether seed trait variation was correlated to the number of seeds that the mother plant produced by calculating the Pearson correlation between each seed trait on the number of seeds.

To analyze the influence of the population, the identity of the mother plant, and the temperature on seedling responses, a threeway ANOVA was performed for each of the three seedling responses, using population as a random factor, the identity of the

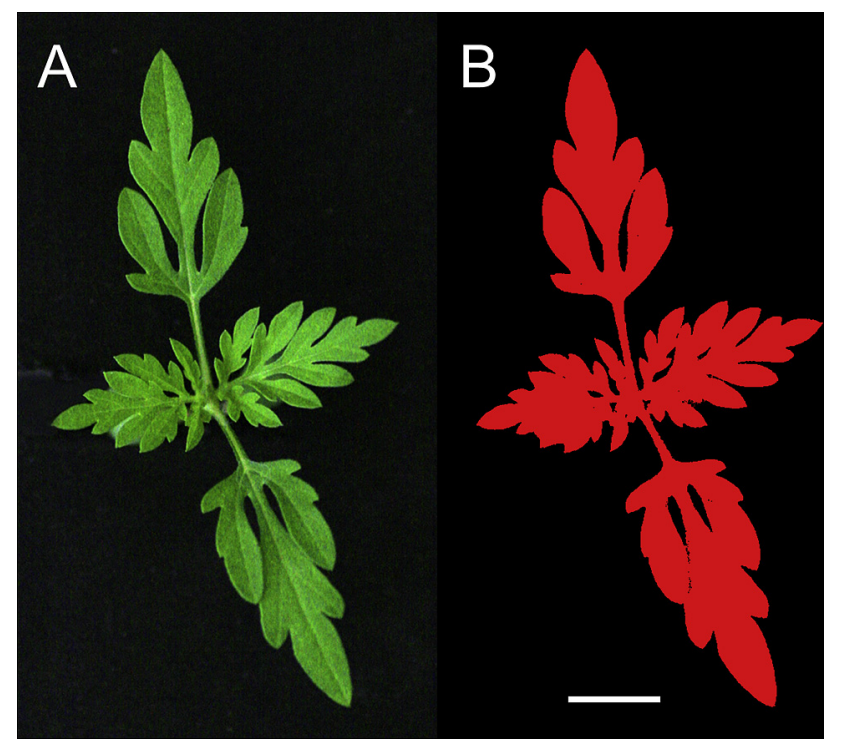

Fig. 2. Illustration of the method of measurement for seedling foliage cover of Ambrosia artemisiifolia. (A) The standard picture taken on a black background. (B) The corresponding output from ImageJ with the thresholder function used to separate foliage cover from the black background. The resulting red area is the surface measured by Image and corresponds to foliage cover measurement. Scale bar $=1 \mathrm{~cm}$. (For interpretation of the references to colour in this figure legend, the reader is referred to the web version of this article.) 
mother plant as a random factor nested in population, and the temperature as a fixed factor. The interaction of the population and mother identity factors with the temperature were added to the model to evaluate whether the population and the mother had the same response to the temperature treatment. Four mothers were observed to cause a rank deficiency because of a lack of germination in one of the temperature conditions. To eliminate this problem, the four mothers were removed from this analysis. To investigate the influence of seed traits on seedling responses, a linear regression of each seed trait on each seedling response was performed. The regressions were conducted separately for each temperature treatment to allow comparison.

In order to test the influence of the temperature treatment on the relationship between seed traits and seedling responses, an analysis of covariance (ANCOVA) was performed for each seed trait influence on every seedling response with the considered seed trait as a covariate and the temperature treatment as a fixed factor.

Prior to conducting the ANOVAs and ANCOVAs, the seed mass, time to germination, foliage cover, and above ground biomass were square root transformed and the seed functional area was logarithm transformed to improve homoscedasticity. The Pearson correlations, nested ANOVA, and descriptive statistics were performed with Minitab ${ }^{\circledR}$ ver. 16.2.2 (Minitab Inc., State College, Pennsylvania, USA). The ANCOVAs, histograms, two-ways ANOVAs, and linear regressions were performed with $\mathrm{R}$ ver. 2.15.0 ( $\mathrm{R}$ Foundation for Statistical Computing, Vienna, Austria).

\section{Results}

\subsection{The structure of seed variation}

Seed mass varied from $2.1 \cdot 10^{-3}$ to $12.7 \cdot 10^{-3} \mathrm{~g}$ with an average of $5.50 \cdot 10^{-3} \pm 0.05 \cdot 10^{-3} \mathrm{~g}$ (mean $\pm \mathrm{SE}$ ). Seed functional area varied from 2.09 to $7.06 \mathrm{~mm}$ with an average of $3.77 \pm 2.85 \cdot 10^{-2} \mathrm{~mm}$. Seed coat lightness values varied from 61 to 192 with an average of $124 \pm 0.744$.

Seed mass was significantly correlated to the functional area $(r=0.829, P$ less than 0.001$)$ and seed coat lightness $(r=-0.114$, $P=0.001)$, but there was no correlation between functional area and seed coat lightness $(r=0.032, P=0.345)$.

The results of the fully-nested ANOVA showed significant variations with all seed traits among populations and mothers (Table 2). The identity of the mother plant explained more than $34 \%$ of the variance of each seed trait variation. Population also explained more than $35 \%$ of the total seed functional area and seed coat lightness variance, but only $16 \%$ of the seed mass total variance. The intra-mother variability also accounted for a large portion of the variance with more than $24 \%$ of the total.
The Pearson correlation calculated to test if the seed traits varied with latitude did not elicit any significance (seed mass: $P=0.085$; seed functional area: $P=0.086$; seed coat lightness: $P=0.224$ ). In contrast, the Pearson correlation calculated to test if the seed traits varied with the number of seeds that the mother produced exhibited a significantly negative impact of seed number on seed mass $(r=-0.258, P=0.014)$, and seed functional area $(r=-0.293$, $P=0.005)$, but not seed coat lightness $(r=-0.506, P=0.597)$.

\subsection{Variation in seedling performance}

Mean, standard error of the mean, minimum, maximum, and the standard deviation of the time to germination, foliage cover and above ground biomass are listed in Table 3. Of the 900 seeds, 780 were germinated (86.7\%), with 418 seeds germinating in warmer conditions (92.9\%) and 362 seeds germinating in colder conditions (84.4\%).

The results of the three-ways ANOVAs performed to investigate the influence of population and the identity of the mother and the interaction with temperature treatment on seedling responses are shown in Table 4. Significant differences were found among populations and mothers for the time to germination and foliage cover. The temperature treatment had an impact on all traits, and this impact varied among populations. While there was no significant above ground biomass differences among populations and mothers, a significant interaction with temperature was highlighted.

\subsection{The influences of seed traits on seedling performance}

Linear regressions performed between seed traits and seedling responses showed that the time to germination decreased with the

Table 3

Mean standard error (SE) of the mean, minimum, and maximum of the seedling response according to temperature treatment.

\begin{tabular}{|c|c|c|c|c|}
\hline & Mean & SE mean & Minimum & Maximum \\
\hline \multicolumn{5}{|c|}{ Both temperature treatments } \\
\hline Time to germination (days) & 11.7 & 0.376 & 2 & 54 \\
\hline Foliage cover $\left(\mathrm{cm}^{2}\right)$ & 4.35 & 0.102 & 0.108 & 11.8 \\
\hline Above ground biomass ( $\mathrm{g}$ ) & 0.129 & $2.87 \mathrm{E}-03$ & $3.20 \mathrm{E}-03$ & 0.351 \\
\hline \multicolumn{5}{|l|}{ Warmer conditions } \\
\hline Time to germination (days) & 4.70 & 0.197 & 2 & 42 \\
\hline Foliage cover $\left(\mathrm{cm}^{2}\right)$ & 6.55 & $9.40 \mathrm{E}-02$ & 0.624 & 11.8 \\
\hline Above ground biomass (g) & 0.187 & $2.72 \mathrm{E}-03$ & $1.88 \mathrm{E}-02$ & 0.351 \\
\hline \multicolumn{5}{|l|}{ Colder conditions } \\
\hline Time to germination (days) & 19.8 & 0.519 & 3 & 54 \\
\hline Foliage cover $\left(\mathrm{cm}^{2}\right)$ & 1.74 & $4.04 \mathrm{E}-02$ & 0.108 & 4.91 \\
\hline Above ground biomass (g) & $6.08 \mathrm{E}-02$ & $2.12 \mathrm{E}-03$ & $3.20 \mathrm{E}-03$ & 0.188 \\
\hline
\end{tabular}

Table 2

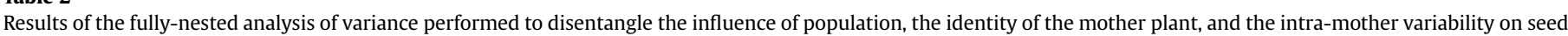
trait variation with the proportion of the variance explained by each factor.

\begin{tabular}{|c|c|c|c|c|}
\hline Source of variation & df & $F$ & $P$ & Proportion of variance explained \\
\hline \multicolumn{5}{|l|}{ Seed mass } \\
\hline Populations & 8 & 4.46 & $<\mathbf{0 . 0 0 1}$ & 16.52 \\
\hline Mother within populations & 81 & 12.06 & $<\mathbf{0 . 0 0 1}$ & 43.84 \\
\hline Intra-mother (error) & 810 & & & 39.64 \\
\hline \multicolumn{5}{|l|}{ Seed functional area } \\
\hline Populations & 8 & 9.57 & $<\mathbf{0 . 0 0 1}$ & 35.86 \\
\hline Mother within populations & 81 & 16.89 & $<\mathbf{0 . 0 0 1}$ & 39.36 \\
\hline Intra-mother (error) & 810 & & & 24.78 \\
\hline \multicolumn{5}{|l|}{ Seed coat lightness } \\
\hline Populations & 8 & 11.87 & $<\mathbf{0 . 0 0 1}$ & 40.37 \\
\hline Mother within populations & 81 & 14.86 & $<\mathbf{0 . 0 0 1}$ & 34.63 \\
\hline Intra-mother (error) & 810 & & & 25.00 \\
\hline
\end{tabular}

Note: Significant $P$-values are in bold. 
Table 4

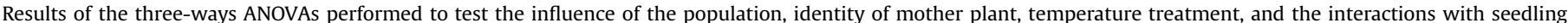
responses.

\begin{tabular}{|c|c|c|c|c|c|c|c|}
\hline \multirow[t]{2}{*}{ Source of variation } & \multirow[t]{2}{*}{$\mathrm{df}$} & \multicolumn{2}{|c|}{ Time to germination } & \multicolumn{2}{|c|}{ Foliage cover } & \multicolumn{2}{|c|}{ Above ground biomass } \\
\hline & & $F$ & $P$ & $F$ & $P$ & $F$ & $P$ \\
\hline Population & 8 & 5.80 & 0.002 & 3.82 & 0.016 & 1.40 & 0.309 \\
\hline Mother (Population) & 77 & 2.51 & $<\mathbf{0 . 0 0 1}$ & 2.94 & $<\mathbf{0 . 0 0 1}$ & 1.36 & 0.088 \\
\hline Temperature & 1 & 492 & $<\mathbf{0 . 0 0 1}$ & 323 & $<\mathbf{0 . 0 0 1}$ & 451 & $<0.001$ \\
\hline Temperature*Population & 8 & 3.49 & 0.002 & 6.42 & $<\mathbf{0 . 0 0 1}$ & 4.44 & $<0.001$ \\
\hline Temperature*Mother (Population) & 77 & 1.05 & 0.361 & 1.03 & 0.406 & 1.37 & 0.025 \\
\hline Error & 575 & & & & & & \\
\hline
\end{tabular}

Note: Significant $P$-values are in bold.

seed functional area in colder conditions (Fig. 3B, $P=0.007$ ). Foliage cover was positively influenced by seed functional area (Fig. 3E, $P$ less than 0.001) and seed mass (Fig. 3D, $P$ less than 0.001 ), but seed coat lightness appeared to have a negative impact in warmer conditions (Fig. 3F, $P$ less than 0.001). Above ground biomass was influenced by seed mass (Fig. 3G, $P$ less than 0.001 ) and seed functional area (Fig. 3H, $P$ less than 0.001).

The influence of temperature treatment on the relationship between seed traits and seedling response was tested using ANCOVAs in order to highlight if the seed traits have a stronger impact in colder conditions than in warmer ones. The test was only significant for the influence of seed coat lightness on foliage cover $\left(F_{1,763}=8.49, P=0.004\right.$, Fig. $\left.3 F\right)$, not being significant for the other relationships ( $P$-values ranged from 0.157 to 0.885 ).

\section{Discussion}

This study sought to understand how seed variation is structured, as well as its consequences on seedling performance. Such knowledge is essential to better grasp the critical factors that influence seedling development in the early stage of life and, thus, the successful establishment of a species.

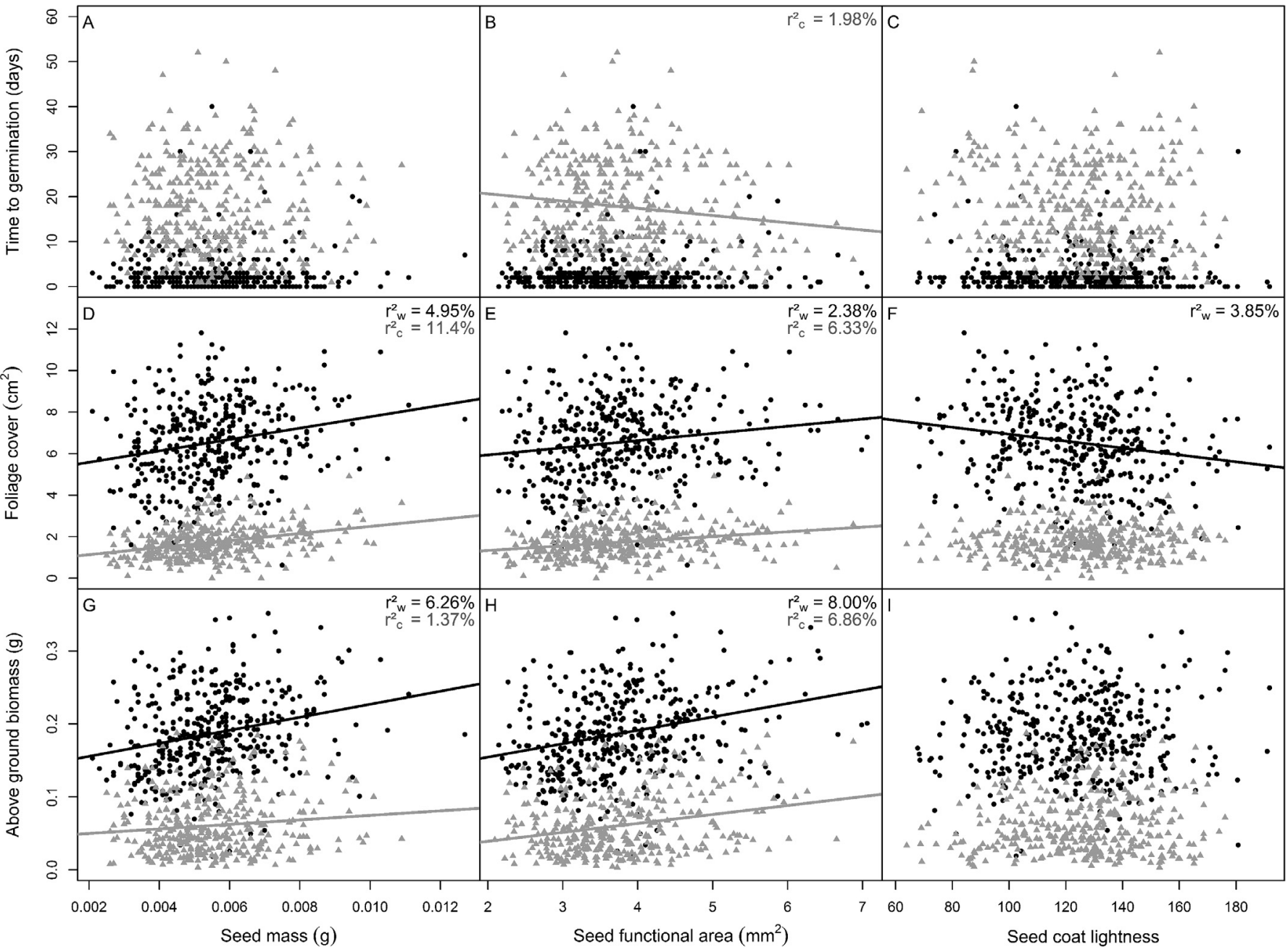

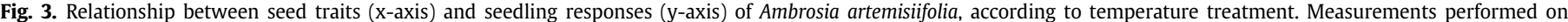

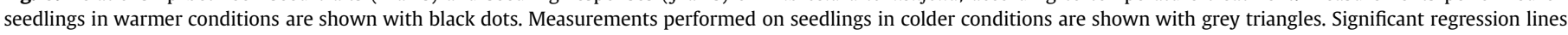
are displayed in the respective colours. Coefficients of determinations are given for significant regressions in the respective colours at the top right of each graph. 


\subsection{The structure of seed variation}

A high variation range in the three measured traits was found: a six-fold variation for seed mass and a three-fold variation for both seed coat lightness and seed functional area. A large range of variation of seed traits had already been observed for other plant species (Michaels et al., 1988; Pitelka et al., 1983; Thompson, 1984), and is consistent with other studies on this particular species (Washitani and Nishiyama, 1992; Fumanal et al., 2007b). Sako et al. (2001) examined a large selection of seed traits of the congeneric species, Ambrosia trifida L., including seed area and colour, and also found high variability among seeds but did not test their influence on seedling performance. As is best presently known, no study has looked into the range of variation of either seed functional area or seed coat lightness in A. artemisiifolia. This variability of seed traits may have been favoured by selection in shifting environments (Fenner and Thompson, 2005; Pitelka et al., 1983; Thompson, 1984). As for the European invasive species, Impatiens glandulifera (Willis and Hulme, 2004), the success of A. artemisiifolia in colonizing heterogeneous environments could be partially explained by such seed variability (Fumanal et al., 2007b). The diversification of phenotypes with the goal of increasing fitness in variable conditions is a bet-hedging strategy (Slatkin, 1974) and is commonly observed in the case of biological invasions (Hotchkiss et al., 2008; Tayeh et al., 2015).

Michaels et al. (1988) observed that in 39 species, intra-mother variability was often the larger contributor to total variance. In fact, Fumanal et al. (2007a,b) found that intra-mother variability was the most important component of total seed mass variance in A. artemisiifolia. In comparison, the results here suggest that seed traits were strongly dependent on population and identity of the mother plant, which together explained more than $60 \%$ of total variance in traits. These influences lasted till the point of seedling development and also impacted time to germination and foliage cover. The strong effects of population and the mother could be made sense of by the very high genetic diversity within populations and mother plants, by genetic differentiation among populations, or by a plastic response to local environmental conditions. High genetic diversity of French populations has been described by Genton et al. (2005) as a result of multiple sources of introduction in France. In the present work, it was observed that there were significant interactions of the population with the temperature treatment for all seedling responses. This could also be a clue to population differentiation in response to environmental conditions in the original locations. However, significant effect of latitude was not seen on seed traits, supporting the idea that variation originated from factors other than climate. The differences among populations could then emanate from other environmental factors, such as edaphic differences, for example. In addition, evidence of active gene flow and population admixture has been documented (Chun et al., 2010), which tends to disprove the hypothesis of population differentiation at the geographic scale this study was based on. These observations are corroborated by previous studies on the same populations (Ortmans et al., submitted).

A significant negative correlation between seed number and seed size was observed. This trade-off suggests a strategy of energy allocation from the parent to the offspring (Smith and Fretwell, 1974) that depends on parent size and of the pool size of resources available for seed production (Venable and Burquez, 1990). The fact that seed size was dependent on the number of seeds produced by the parent is another explanation for the strong impact of the mother plant on seed traits. As well, this could be a clue that there was a resource limitation in certain original locations influencing parent size or seed production (Smith and Fretwell, 1974; Venable, 1992).

\subsection{The influences of seed traits on seedling performance}

The seed mass did not impact the time to germination, but did indeed affect foliage cover and above ground biomass. Heavier seeds also had faster foliage development and produced a larger final biomass. Seed mass variation is known to frequently influence germination kinetics (Harper et al., 1970; Roach and Wulff, 1987). Seed functional area had an effect on all seedling responses - seeds with a larger functional area germinated earlier in colder conditions, had quicker foliage development and produced a higher final biomass than seeds with a smaller functional area. These observations suggest that the place available for the embryo in the seed and the resources included have strong consequences for further development of the plant.

It is interesting that there was a very minimal effect of seed traits on time to germination as a relationship between seed size and time to germination has been found for the congeneric species, A. trifida (Schutte et al., 2008).

It was seen that seed functional area had approximately the same effect that seed mass, with a slightly supplementary impact, exerted on time to germination. This is probably a consequence of the strong correlation between these two traits that was highlighted with the Pearson correlation test $(r=0.829$, $\mathrm{p}<0.001$ ).

In contrast to the other seed traits, seed coat lightness had a very negligible effect on the seedlings. This may refute a previously reported germinative-restrictive influence of seed coat on seedling performance (Debeaujon et al., 2000).

\subsection{The influence of the temperature treatment}

Temperature treatment had a very strong impact on all seedling responses, denoting an important phenotypic plasticity of the species (Sultan, 2000), this plasticity already having been highlighted by several authors (Paquin and Aarssen, 2004; Qin et al., 2012). The temperature selected for the colder condition had a negative effect on plant development, possibly a signal that establishment could slow down in countries with colder spring temperatures. However, these aspects cannot be studied without taking into account other climatic factors, such as the photoperiod and the first frost occurrence known to limit the species (Baskin and Baskin, 1980; Chapman et al., 2014; Deen et al., 1998), as well as field observations (Leiblein-Wild et al., 2014; Ortmans et al., submitted).

Surprisingly, an effect of the temperature on the relationship between seed traits and seedling response was barely detected. This could indicate that: 1) the seed reserve is not especially beneficial to the seedling in stressful conditions; 2) despite the strong impact of temperature treatment, the colder condition was not harsh enough to induce stress; 3 ) apart from temperature, the controlled conditions were too favourable versus those outdoors for truly marked physiological stress.

In this study, very high variability in seed traits and seedling performance was observed that could be one of the A. artemisiifolia L. species' characteristics explaining invasion success, especially in variable environments (Willis and Hulme, 2004). A large part of the variation in seed traits and seedling performance was attributable to the population of origin and to the identity of the mother plant. These factors even had an impact on seedling responses to temperature treatment. In contrast, seed trait variation was not influenced by latitude of the original location, though this excludes the role of climate in seed trait expression. Seed mass and seed functional area appeared to be correlated and to have strong consequences for seedling performance. 


\section{Contributions}

Conceived and designed the experiments: Monty, Ortmans, Mahy.

Performed the experiments: Ortmans, Monty.

Analyzed the data: Ortmans, Monty.

Contributed reagents/materials/analysis tools: Mahy, Monty.

Wrote the paper: Ortmans, Monty, Mahy.

\section{Acknowledgements}

The authors thank Florian Moreira for his help during data collection. This study was funded by the Fonds de la Recherche dans l'Industrie et dans l'Agriculture (FRIA). The work was also supported by the Fonds de la Recherche Scientifique - FNRS (grant number 1.5061.12).

\section{References}

Baskin, C.C., Baskin, J.M., 2001. Seeds: Ecology, Biogeography, and Evolution of Dormancy and Germination. American Journal of Botany. Academic Press, New York, USA. http://dx.doi.org/10.2307/2656711.

Baskin, J., Baskin, C., 1980. Ecophysiology of secondary dormancy in seeds of Ambrosia artemisiifolia. Ecology 61, 475-480.

Bassett, I.J., Crompton, C.W., 1975. The biology of Canadian weeds. Can. J. Plant Sci. 55, 463-476. http://dx.doi.org/10.4141/cjps75-072.

Bazzaz, F.A., 1974. Ecophysiology of Ambrosia artemisiifolia: a successful dominant. Ecology 55, 112-119.

Biere, A., 1991. Parental effects in Lychnis flos-cuculi. I: seed size, germination and seedling performance in a controlled environment. Evol. Biol. 3, 447-465 http://dx.doi.org/10.1046/j.1420-9101.1991.4030447.x.

Cain, M.L., Milligan, B.G., Strand, A.E., 2000. Long-distance seed dispersal in plant populations. Am. J. Bot. 87, 1217-1227.

Chapman, D.S., Haynes, T., Beal, S., Essl, F., Bullock, J.M., 2014. Phenology predicts the native and invasive range limits of common ragweed. Glob. Chang. Biol. 20, 192-202. http://dx.doi.org/10.1111/gcb.12380.

Chauvel, B., Dessaint, F., Cardinal-Legrand, C., Bretagnolle, F., 2006. The historica spread of Ambrosia artemisiifolia L. in France from herbarium records. Biogeography 33, 665-673. http://dx.doi.org/10.1111/j.1365-2699.2005.01401.x.

Chun, Y.J., Fumanal, B., Laitung, B., Bretagnolle, F., 2010. Gene flow and population admixture as the primary post-invasion processes in common ragweed ( $\mathrm{Am}$ brosia artemisiifolia) populations in France. New Phytol. 185, 1100-1107. http:/ dx.doi.org/10.1111/j.1469-8137.2009.03129.x.

Debeaujon, I., Léon-Kloosterziel, K.M., Koornneef, M., 2000. Influence of the testa on seed dormancy, germination, and longevity in Arabidopsis. Plant Physiol. 122 403-414. http://dx.doi.org/10.1104/pp.122.2.403.

Deen, W., Hunt, T., Swanton, J., 1998. Influence of temperature, photoperiod, and irradiance on the phenological development of common ragweed (Ambrosia artemisiifolia). Weed Sci. 46, 555-560.

Dolan, R.W., 1984. The effect of seed size and maternal source on individual size in a population of Ludwigia leptocarpa (Onagraceae). Am. J. Bot. 71, 1302-1307.

Durán, J.M., Retamal, N., 1989. Coat structure and regulation of dormancy in Sinapis arvensis L. seeds. Plant Physiol. 135, 218-222. http://dx.doi.org/10.1016/S01761617(89)80180-4.

Fenesi, A., Albert, Á.J., Ruprecht, E., 2014. Fine-tuned ability to predict future competitive environment in Ambrosia artemisiifolia seeds. Weed Res. 54, 58-69. http://dx.doi.org/10.1111/wre.12048.

Fenner, M., Thompson, K., 2005. The Ecology of Seeds, Annals of Botany. Cambridge University Press, Cambridge, United Kingdom. http://dx.doi.org/10.1093/aob/ mcj016.

Fumanal, B., Chauvel, B., Bretagnolle, F., 2007a. Estimation of pollen and seed production of common ragweed in France. Ann. Agric. Environ. Med. 14, 233-236. http://dx.doi.org/10.1016/j.neurol.2011.08.009.

Fumanal, B., Chauvel, B., Sabatier, A., Bretagnolle, F., 2007b. Variability and cryptic heteromorphism of Ambrosia artemisiifolia seeds: what consequences for its invasion in France? Ann. Bot. 100, 305-313. http://dx.doi.org/10.1093/aob/ mcm108.

Fumanal, B., Gaudot, I., Bretagnolle, F., 2008. Seed-bank dynamics in the invasive plant, Ambrosia artemisiifolia L. Seed Sci. Res. 18, 101-114. http://dx.doi.org/ 10.1017/S0960258508974316.

Gebben, A.I., 1965. The Ecology of Common Ragweed, Ambrosia artemisiifolia L., in Southeastern Michigan. Ph.D. dissertation. University of Michigan, Ann Arbor, Michigan, USA.

Genton, B.J., Shykoff, J.A., Giraud, T., 2005. High genetic diversity in French invasive populations of common ragweed, Ambrosia artemisiifolia, as a result of multiple sources of introduction. Mol. Ecol. 14, 4275-4285. http://dx.doi.org/10.1111/ j.1365-294X.2005.02750.x.

Gross, K.L., 1984. Effects of seed size and growth form on seedling establishment of six monocarpic perennial plants. Ecology 72, 369. http://dx.doi.org/10.2307
2260053.

Gross, K.L., Smith, A.D., 1991. Seed mass and emergence time effects on performance of Panicum dichotomiflorum Michx. across environments. Oecologia 87, $270-278$.

Guillemin, J.P., Chauvel, B., 2011. Effects of the seed weight and burial depth on the seed behavior of common ragweed (Ambrosia artemisiifolia). Weed Biol. Manag. 11, 217-223.

Harper, J.L., 1977. Population Biology of Plants. Academic Press, London, United Kingdom.

Harper, J.L., Lovell, P.H., Moore, K.G., 1970. The shapes and sizes of seeds. Annu. Rev. Ecol. Syst. 1, 327-356. http://dx.doi.org/10.1146/annurev.es.01.110170.001551.

Heckel, M.E., 1906. Sur l'Ambrosia artemisiæfolia L. et sa naturalisation en France. Bull. Soc. Bot. Fr. 53, 600-620. http://dx.doi.org/10.1080/ 00378941.1906.10831212.

Hotchkiss, E.E., DiTommaso, A., Brainard, D.C., Mohler, C.L., 2008. Survival and performance of the invasive vine vincetoxicum rossicum (Apocynaceae) from seeds of different embryo number under two light environments. Am. J. Bot. 95, 447-453. http://dx.doi.org/10.3732/ajb.95.4.447.

Kazinczi, G., Béres, I., Novák, R., Bíró, K., Pathy, Z., 2008. Common ragweed (Ambrosia artemisiifolia): a review with special regards to the results in Hungary. I. Taxonomy, origin and distribution, morphology, life cycle and reproduction strategy. Herbologia 9, 55-91.

Khan, M., Cavers, P.B., Kane, M., Thompson, K., 1997. Role of the pigmented seed coat of proso millet (Panicum miliaceum L.) in imbibition, germination and seed persistence. Seed Sci. Res. 7, 21-26. http://dx.doi.org/10.1017/ S0960258500003329.

Kleunen, M. Van, Fischer, M., Schmid, B., 2001. Effects of intraspecific competition on size variation and reproductive allocation in a clonal plant. Oikos 94, 515-524. http://dx.doi.org/10.1034/j.1600-0706.2001.940313.x.

Laaidi, M., Thibaudon, M., Besancenot, J.P., 2003. Two statistical approaches to forecasting the start and duration of the pollen season of Ambrosia in the area of Lyon (France). Int. J. Biometeorol. 48, 65-73. http://dx.doi.org/10.1007/ s00484-003-0182-2.

Leiblein-Wild, M.C., Kaviani, R., Tackenberg O, 2014 Germination and seedling frost tolerance differ between the native and invasive range in common ragweed. Oecologia 174, 739-750. http://dx.doi.org/10.1007/s00442-013-2813-

López, M.G., Wulff, A.F., Poggio, L., Xifreda, C.C., 2008. South African fireweed Senecio madagascariensis (Asteraceae) in Argentina: relevance of chromosome studies to its systematics. Bot. J. Linn. Soc. 158, 613-620.

Mandák, B., Pyšek, P., 2001. The effects of light quality, nitrate concentration and presence of bracteoles on germination of different fruit types in the heterocarpous Atriplex sagittata. Ecology 89, 149-158. http://dx.doi.org/10.1046/ j.1365-2745.2001.00537x.

Michaels, H.J., Benner, B., Hartgerink, A.P., Lee, T.D., Rice, S., Willson, M.F., Bertin, R.I., 1988. Seed size variation: magnitude, distribution, and ecological correlates. Evol. Ecol. 2, 157-166. http://dx.doi.org/10.1007/BF02067274.

Moegenburg, S.M., 1996. Sabal palmetto seed size: causes of variation, choices of predators, and consequences for seedlings. Oecologia 106, 539-543. http:// dx.doi.org/10.1007/BF00329713.

Moles, A.T., Ackerly, D.D., Tweddle, J.C., Dickie, J.B., Smith, R., Leishman, M.R. Mayfield, M.M., Pitman, A., Wood, J.T., Westoby, M., 2007. Global patterns in seed size. Glob. Ecol. Biogeogr. 16, 109-116. http://dx.doi.org/10.1111/j.1466822X.2006.00259.x.

Monty, A., Bizoux, J.P., Escarré, J., Mahy, G., 2013. Rapid plant invasion in distinct climates involves different sources of phenotypic variation. PLoS One 8, e55627. http://dx.doi.org/10.1371/journal.pone.0055627.

Monty, A., Mahy, G., 2009. Clinal differentiation during invasion: Senecio inaequidens along altitudinal gradients in Europe. Oecologia 159, 305-315. http:// dx.doi.org/10.1007/s00442-008-1228-2.

Paquin, V., Aarssen, L.W., 2004. Allometric gender allocation in Ambrosia artemisiifolia (Asteraceae) has adaptive plasticity. Am. J. Bot. 91, 430-438. http:// dx.doi.org/10.3732/ajb.91.3.430.

Pitelka, L.F., Thayer, M.E., Hansen, S.B., 1983. Variation in achene weight in Aster acuminatus. Can. J. Bot. 61, 1415-1420.

Powell, A.A., 1989. The importance of genetically determined seed coat characteristics to seed quality in grain legumes. Ann. Bot. 63, 169-175.

Qin, Z., Mao, D.J., Quan, G.M., Zhang, J., Xie, J.F., DiTommaso, A., 2012. Physiological and morphological responses of invasive Ambrosia artemisiifolia (common ragweed) to different irradiances. Botany 90, 1284-1294. http://dx.doi.org/ 10.1139/b2012-096.

Rice, K.J., Dyer, A.R., 2001. Seed aging, delayed germination and reduced competitive ability in Bromus tectorum. Plant Ecol. 155, 237-243.

Roach, D.A., Wulff, R.D., 1987. Maternal effects in plants. Annu. Rev. Ecol. Syst. 18, 209-235. http://dx.doi.org/10.1146/annurev.es.18.110187.001233.

Sako, Y., Regnier, E.E., Daoust, T., Fujimura, K., Kent Harrison, S., McDonald, M.B., 2001. Computer image analysis and classification of giant ragweed seeds. Weed Sci. 49, 738-745. http://dx.doi.org/10.1614/0043-1745(2001)049[0738:CIAACO] 2.0.CO;2.

Schutte, B.J., Regnier, E.E., Harrison, S.K., 2008. The association between seed size and seed longevity among maternal families in Ambrosia trifida L. populations. Seed Sci. Res. 18, 201-211. http://dx.doi.org/10.1017/S0960258508082974.

Simons, A.M., Johnston, M.O., 2000. Variation in seed traits of Lobelia inflata (Campanulaceae): sources and fitness consequences. Am. J. Bot. 87, 124-132. http://dx.doi.org/10.2307/2656690. 
46

W. Ortmans et al. / Act Oecologica 71 (2016) 39-46

Skálová, H., Havlíčková, V., Pyšek, P., 2012. Seedling traits, plasticity and local defferentiation as strategies of invasive species of impatiens in central Europe. Ann. Bot. 110, 1429-1438. http://dx.doi.org/10.1093/aob/mcr316.

Slatkin, M., 1974. Hedging one's evolutionary bets. Nature 250, 704-705.

Smith, C.C., Fretwell, S.D., 1974. The optimal balance between size and number of offspring. Am. Nat. 108, 499-506. http://dx.doi.org/10.1086/282929.

Smith, M., Cecchi, L., Skjøth, C.A., Rarer, G., Šikoparija, B., 2013. Common ragweed: a threat to environmental health in Europe. Environ. Int. 61, 115-126. http:// dx.doi.org/10.1016/j.envint.2013.08.005.

Sõber, V., Ramula, S., 2013. Seed number and environmental conditions do not explain seed size variability for the invasive herb Lupinus polyphyllus. Plant Ecol. 214, 883-892. http://dx.doi.org/10.1007/s11258-013-0216-8.

Solomon, S., Quin, D., Manning, M., Marquis, M., Averyt, K., Tignor, M.M.B., LeRoy Miller, H., 2007. Climate Change 2007: the Physical Science Basis. Contribution of Working Group I to the Fourth Assessment. Report of the Intergovernmental Panel on Climate Change. Cambridge University Press, Cambridge, United Kingdom.

Stanton, M.L., 1984. Seed variation in wild radish: effect of seed size on components of seedling and adult fitness. Ecology 65, 1105-1112.

Sultan, S.E., 2000. Phenotypic plasticity for plant development, function and life history. Trends Plant Sci. 5, 537-542. http://dx.doi.org/10.1016/s1360-1385(00) 01797-0.

Susko, D.J., Lovett-Doust, L., 2000. Patterns of seed mass variation and their effects on seedling traits in Alliaria petiolate (Brassicaceae). Am. J. Bot. 87, 56-66.

Tautenhahn, S., Heilmeier, H., Go, L., Klotz, S., Wirth, C., 2008. On the biogeography of seed mass in Germany - distribution patterns and environmental correlates. Europe 31, 457-468. http://dx.doi.org/10.1111/j.2008.0906-7590.05439.x.

Tayeh, A., Hufbauer, R.A., Estoup, A., Ravigné, V., Frachon, L., Facon, B., 2015. Biological invasion and biological control select for different life histories. Nat. Commune. 6, 7268. http://dx.doi.org/10.1038/ncomms8268.
Thompson, J.N., 1984. Variation among individual seed masses in Lomatium gray (Umbelliferae) under controlled conditions: magnitude and partitioning of the variance. Ecology 65, 626-631.

Venge, V., Heuch, I., Vandvik, V., 2004. Do seed mass and family affect germination and juvenile performance in Knautia arvensis? A study using failure-time methods. Alta Oecol. 25, 169-178. http://dx.doi.org/10.1016/ j.actao.2004.01.002.

Venable, D.L., 1992. Size-number trade-offs and the variation of seed size with plant resource status. Am. Nat. 140, 287-304. http://dx.doi.org/10.1086/285413.

Venable, D.L., Brown, J.S., 1988. The selective interactions of dispersal, dormancy, and seed size as adaptations for reducing risk in variable environments. Am. Nat. 131, 360-384. http://dx.doi.org/10.1086/284795.

Venable, D.L., Burquez, A.M., 1990. Quantitative genetics of size, shape, life-history, and fruit characteristics of the seed heteromorphic composite Heterosperma pinnatum. II. Correlation structure. Evol. (N. Y) 44, 1748-1763.

Washitani, I., Nishiyama, S., 1992. Effects of seed size and seedling emergence time on the fitness components of Ambrosia trifid and A. artemisiaefolia var. elation in competition with grass perennials. Plant Species Biol. 7, 11-19. http:// dx.doi.org/10.1111/j.1442-1984.1992.tb00238.x.

Willis, S.G., Hulme, P.E., 2004. Environmental severity and variation in the reproductive traits of Impatiens glandulifera. Funct. Ecol. 18, 887-898. http:// dx.doi.org/10.1111/j.0269-8463.2004.00907.x.

Wulff, R.D., 1986a. Seed size variation in Desmodium paniculatum. II. Effects on seedling growth and physiological performance. Ecology 74, 99-114.

Wulff, R.D., 1986b. Seed size variation in Desmodium paniculatum. III. Effects on reproductive yield and competitive ability. Ecology 74, 115-121. http:// dx.doi.org/10.2307/2260352.

Wyatt, J.E., 1977. Seed coat and water absorption properties of seed of near-isogenic snap bean lines differing in seed coat color. Am. Soc. Hortic. Sci. 102, 478-480. 